\title{
Solution Versus Gas-Phase Modification of Peptide Cations with NHS-Ester Reagents
}

\author{
Marija Mentinova, Nathan Z. Barefoot, Scott A. McLuckey \\ Department of Chemistry, Purdue University, West Lafayette, IN 47907-2084, USA
}

\begin{abstract}
A comparison between solution and gas phase modification of primary amine sites in model peptide cations with $\mathrm{N}$-hydroxysuccinimide (NHS) ester reagents is presented. In all peptides, the site of modification in solution was directed to the $\mathrm{N}$-terminus by conducting reactions at $\mathrm{pH}=5$, whereas for the same peptides, a lysine residue was preferentially modified in the gas phase. The difference in pKa values of the $\mathrm{N}$-terminus and $\varepsilon$-amino group of the lysine allows for a degree of control over sites of protonation of the peptides in aqueous solution. With removal of the dielectric and multiple charging of the peptide ions in the gas phase, the accommodation of excess charge can affect the preferred sites of reaction. Interaction of the lone pair of the primary nitrogen with a proton reduces its nucleophilicity and, as a result, its reactivity towards NHS-esters. While no evidence for reaction of the N-terminus with sulfo-NHS-acetate was noted in the model peptide cations, a charge inversion experiment using bis[sulfosuccinimidyl] suberate, a cross-linking reagent with two sulfo-NHS-ester functionalities, showed modification of the $\mathrm{N}$-terminus. Hence, an unprotonated $\mathrm{N}$-terminus can serve as a nucleophile to displace NHS, which suggests that its lack of reactivity with the peptide cations is likely due to the participation of the $\mathrm{N}$-terminus in solvating excess charge.
\end{abstract}

Key words: Gas phase ion/ion reactions, $N$-hydroxysulfosuccinimide esters, Gas-phase bioconjugation, Gas phase versus solution phase reactions

\section{Introduction}

$\mathrm{T}$ he nature of the ion subjected to structural interrogation via tandem mass spectrometry is usually determined by the ionization method. Ion/ion reactions [1-4], which were enabled by the advent of ionization methods that can generate multiply-charged ions, have proven to be effective in altering ion types from one form to another in the gas phase. This capability allows for the decoupling of the ionization conditions from the ion type available for structural characterization. Many ion types readily generated by common ionization sources (i.e., molecular ion

Electronic supplementary material The online version of this article (doi:10.1007/s13361-011-0291-9) contains supplementary material, which is available to authorized users.

Correspondence to: Scott A. McLuckey; e-mail: mcluckey@purdue.edu
$\left[\mathrm{M}^{+\bullet}\right]$, protonated molecule $[\mathrm{M}+\mathrm{H}]^{+}$, deprotonated molecule $[\mathrm{M}-\mathrm{H}]^{-}$, multiply-charged ions, etc.) can be manipulated in the gas phase by selecting an appropriate oppositely charged reagent [5]. Common examples of ion type manipulation via ion/ion chemistry include, inter alia, the reduction of charge via proton transfer $[6,7]$, the inversion of charge via multiple ion transfers in a single collision $[8,9]$, the increase of charge via sequential charge inversion reactions $[10,11]$, the incorporation of metal ions into peptides either via metal transfer reactions [12, 13], or metal cation attachment [14], and the conversion of multiply-charged bio-ions to radical species via electron transfer [15-17]. These types of ion transformations coupled with tandem mass spectrometry have been applied in the identification and structural characterization of peptides, proteins [18, 19], and oligonucleotides [20, 21].

In addition to the charged particle transfer processes shown to take place in the gas phase, covalent bond 
formation between oppositely charged reactants has also been noted. Recently, Schiff base chemistry resulting in covalent bond formation has been demonstrated during an ion/ion reaction between an aldehyde-containing reagent anion [e.g., singly deprotonated 4-formyl-1,3-benzenedisulfonic acid (FBDSA)] and a primary amine group in multiply protonated peptide ions [22]. Schiff base formation has also been implemented in conjunction with charge inversion involving an ion/ion reaction between singly protonated peptide ions and doubly deprotonated FBDSA [23]. Collisioninduced dissociation (CID) of the resulting modified peptide anions gave rise to richer informative structural information than did CID of either the singly protonated or singly deprotonated peptide. Schiff base formation in conjunction with charge inversion has also been applied to tryptic and intramolecularly disulfide-linked peptides [24]. Collisioninduced dissociation of these modified peptide ions led to fragmentation that is complementary to that noted for unmodified versions of the same peptides, which was attributed to the charge sequestration at the highly acidic sulfonate groups of FBDSA. This selective covalent bond formation has inspired the exploration of other selective modification chemistries in the gas phase.

The ability to covalently modify various functional groups via ion/ion reactions presents new means for iontype transformations in the gas phase. Covalent modification of primary amines in multiply charged peptide cations and anions using $N$-hydroxysulfosuccinimide (sulfo-NHS) and $N$-hydroxysuccinimide (NHS) based derivatives, respectively, has been demonstrated [25]. The two prerequisites for a successful covalent modification in the gas phase include the presence of an unprotonated primary amine site in the analyte and the presence of a "sticky" group on the reagent ion, which facilitates formation of a long-lived complex between the reactants. In this process, the carbonyl carbon of the NHS ester undergoes a nucleophilic attack by the primary amine, resulting in loss of NHS (or sulfo-NHS) and formation of an amide bond. Loss of the NHS or sulfoNHS groups represents a signature of the covalent modification chemistry. In addition to covalent bond formation at a single primary amine site, sulfo-NHS derivatives have also been implemented in covalent cross-linking of two primary amine sites [26]. Intra- and inter-molecular cross-linking of gaseous peptide cations have been achieved using homobifunctional, sulfo-NHS-based cross-linker anions. Loss of two sulfo-NHS functionalities represents a signature of the covalent modification and cross-linking process. Subsequent collisional activation of the intra-molecularly cross-linked peptides results in fragment ions containing the cross-link between two primary amine sites, while collisional activation of the inter-molecularly cross-linked peptides results in one peptide cross-linked to fragment ions of the second peptide.

Covalent modification of primary amines in solution with NHS and sulfo-NHS based reagents is a commonly applied bioconjugation technique. Coupled with mass spectrometry, bioconjugation of proteins and peptides is used to facilitate ionization [27], quantification [28, 29], and structural characterization $[30,31]$. The reactivity of primary amine groups in biomolecules, (i.e., N-terminus and the $\varepsilon-\mathrm{NH}_{2}$ group of a lysine residue) towards NHS derivatives in solution has been explored. One of the early reports on using covalent modifications in solution with mass spectrometry examined the relative reactivities of primary amine groups in Aplysia egg-laying hormone with the $N$-hydroxysuccinimide ester of biotin [32]. In a similar study, Novak et al. have probed the reactivity of the $\mathrm{N}$-terminal and $\varepsilon$-lysine amino groups of ubiquitin in a reaction with $\mathrm{N}$-hydroxysuccinimidyl acetate, under native and denaturing conditions [33]. Their findings suggest higher reactivity of N-terminus primary amine in solution compared to Lys side chain amine groups. The Lys side chains are possibly involved in hydrogen bonding interactions with other portions of the protein, hence reducing their reactivity towards the NHSacetate reagent. Since the NHS/sulfo-NHS ester modification chemistry involves a nucleophilic attack on a carbonyl carbon by the primary amine, it is the nucleophilicities of the various primary amines that govern where modifications occur. It is well established that the ionization state of the polypeptide in solution plays a role in determining the site of modification. The N-terminus has a $\mathrm{pKa}$ value of 7.6-8.0, while the $\varepsilon$-amino of Lys has a pKa of 9.3-9.5 [34]. Since the pKa value of the $\mathrm{N}$-terminus is lower than that of Lys, it can be selectively modified by adjusting the solution $\mathrm{pH}$ so that the Lys is protonated and the N-terminus is not [35]. If modification of both sites is desired, the $\mathrm{pH}$ of the reaction can be increased to a neutral or more basic $\mathrm{pH}$ so that neither site is protonated. In contrast, Laskin and coworkers have shown that the $\mathrm{N}$-terminus does not make a significant contribution to binding in the covalent immobilization on NHS-terminated surfaces by soft landing of gaseous peptide ions [36]. The latter work raises the question as to whether there is a significant difference in the solution and gas phase reactivities of peptide ions toward NHS-ester reagents. In this report, we compare the reactivity of primary amines in gaseous peptide cations towards sulfo-NHS-based reagent anions in the gas phase to that in solution.

\section{Experimental}

\section{Materials}

Methanol and glacial acetic acid were purchased from Mallinckrodt (Phillipsburg, NJ, USA). Peptides RKRARAA, RARARKA, RARARAA, ARAKRAR, and ARAKARA were custom synthesized by CPC Scientific (San Jose, C, USA). Reagents sulfo-NHS-acetate (sulfosuccinimidyl acetate), sulfoNHS-AMCA (sulfosuccinimidyl-7-amino-4-methylcoumarin3 -acetate), and bis[sulfosuccinimidyl] suberate $\left(\mathrm{BS}^{3}\right)$ were obtained from Thermo Fisher Scientific Inc. (Rockford, IL, USA), while biotin-NHS (Biotin $N$-hydroxysuccinimide ester) was purchased from Alfa Aesar (Ward Hill, MA, USA). All 
peptide solutions for positive electrospray were prepared in 49.5:49.5:1 ( vol $/ \mathrm{vol} / \mathrm{vol})$ water $/ \mathrm{methanol} /$ acetic acid mixture at a concentration of $\sim 50 \mu \mathrm{M}$. The reagent solutions were prepared at a concentration of approximately $2 \mathrm{mM}$ in equal parts of methanol and water. The solution phase modification of the peptides was achieved following a well established procedure [37]. Briefly, the peptide and ten molar excess of the reagent were mixed in sodium carbonate buffer $(0.1 \mathrm{M})$ at $\mathrm{pH}$ $\sim 5$ and allowed to react for $2 \mathrm{~h}$ at room temperature. The modified peptides were separated from the excess reagent using reversed phase HPLC and the obtained fractions were lyophilized. The modified dry peptide was then dissolved in solution for positive ESI.

\section{Mass Spectrometry}

All ion/ion reactions were performed on a prototype version of a triple quadrupole/linear ion trap, QTRAP mass spectrometer [38] (Applied Biosystems/MDS Sciex, Concord, ON, Canada), equipped with a home-built dual nano-electrospray ionization source [39]. The procedure for the covalent modification of peptide cations with sulfo-NHS-based reagents has already been published [25]. Briefly, the peptide and reagent ions were independently mass selected in Q1 and subsequently transferred to Q2, the collision cell. The ions of opposite polarity were allowed to react under mutual storage mode for various times [40]. The ion/ion reaction products were then transferred to Q3. In this transfer step, the product ions were accelerated between Q2 and Q3 to collisionally dissociate any residual sulfo-NHS molecules via beam type CID. The covalently modified peptide ions were mass selected in Q3 where they were collisionally activated using ion-trap CID. Following the ion trap collisional activation, the modified product ions were mass analyzed using mass-selective axial ejection (MSAE) [41]. Additionally, doubly protonated forms of the solution phase modified ions were mass selected and subjected to collisional activation in Q3. These spectra were compared to the CID spectra of the gas phase modified peptides.

\section{Results and Discussion}

A variety of sulfo-NHS based reagents are commercially available for the covalent modification of primary amines in solution. Gaseous sulfo-NHS-based anions have also been shown to be capable of covalently modifying poly-protonated peptides via ion/ion reactions as well. The sulfonate group on the NHS ring facilitates the solubility of the reagents in aqueous solution and the ionization of the reagents in negative polarity. Additionally, the sulfonate group engages in relatively strong acid-base interactions with protonated sites in the peptides, resulting in the long lived complex formation necessary for the covalent modification process in the gas phase. The presence of an unprotonated primary amine site in the polypeptide is the other criterion for successful gas phase bioconjugation. In this study, we make comparisons between solution and gas phase modified peptides to evaluate the effects that play a role in the covalent modification process of primary amines with NHS-based reagents.

The ion/ion reaction between a triply protonated RKRARAA and singly charged sulfo-NHS-acetate anions resulted in the formation of [RKRARAA+(sulfo-NHSacetate) $+2 \mathrm{H}]^{2+}$. Beam type CID of this complex resulted in the loss of a neutral sulfo-NHS molecule, leaving an acetate-modified peptide. Subsequent collisional activation of the $[\text { RKRARAA }+ \text { acetate }+2 \mathrm{H}]^{2+}$ ion population results in the product ion spectrum shown in Figure 1a. This spectrum shows a series of acetate-modified $b_{2}-b_{6}$ ions but unfortunately does not provide definitive information on the precise location of the acetate modification. In these ions, the modification can reside either at the $\mathrm{N}$-terminus or the side chain primary amine of Lys and the modified b-ions are consistent with modification at either site. A modified $b_{1}$ ion, however, is not observed in the spectrum, which would be the only ion to suggest modification is at the $\mathrm{N}$-terminus primary amine site. As expected, none of the y-type ions appearing in the spectrum are modified except for the $\mathrm{y}_{6}$ ion. This ion contains the Lys residue suggesting that at least some of the modification resides at that $\varepsilon$-primary amine site. The complementary unmodified $b_{1}$ ion also appears in the spectrum. The absence of complementary modified $b_{1}$-ion and unmodified $\mathrm{y}_{6}$-ions is suggestive that little or no modification of the N-terminus took place. For comparison, the same peptide was covalently modified in solution with sulfo-NHS-acetate at $\mathrm{pH}=5$. As mentioned above, the $\mathrm{N}-$ terminus primary amine site can be selectively modified at slightly acidic $\mathrm{pH}$ values due to its lower $\mathrm{pKa}$ value relative to that of the $\varepsilon$-primary amine in Lys. The goal of the solution phase modification is to compare the dissociation pattern of the peptide modified only at the $\mathrm{N}$-terminus to the dissociation of the peptide modified in the gas phase with the same reagent. The ion trap CID spectrum of $[\text { RKRARAA }+ \text { acetate }+2 \mathrm{H}]^{2+}$ generated in solution is shown in Figure $1 b$. A complete series of modified $b_{1}-b_{6}$ ions is observed. An unmodified $b_{1}$ ion and its complementary modified $\mathrm{y}_{6}$ ions are also seen in very low abundances suggesting that a small portion of the peptide population has the modification at the Lys side chain. Since multiple Arg residues are present in the peptide, portions of the Arg side chain can easily be cleaved under low energy CID. Therefore, the $m / z$ value for the unmodified $b_{1}$ ion can also correspond to a modified $b_{1}$ ion that has lost 42 Da from the Arg side chain (see below as this is addressed further in the discussion of Figure 2 and Figure S-2). The rest of the y-type ions in the spectrum are not modified. The major difference between the two CID spectra in Figure 1 is the appearance of the modified $\mathrm{b}_{1}$ and fairly abundant unmodified $\mathrm{y}_{6}$ ions in the solution modified peptide spectrum, while unmodified $b_{1}$ and modified $\mathrm{y}_{6}$ ions are present in the gas phase modified peptide spectrum. The absence or presence of these diagnostic product ions in each of the CID spectra in Figure 1 strongly suggests distinct preferences for the site of modification in solution versus the gas phase. 


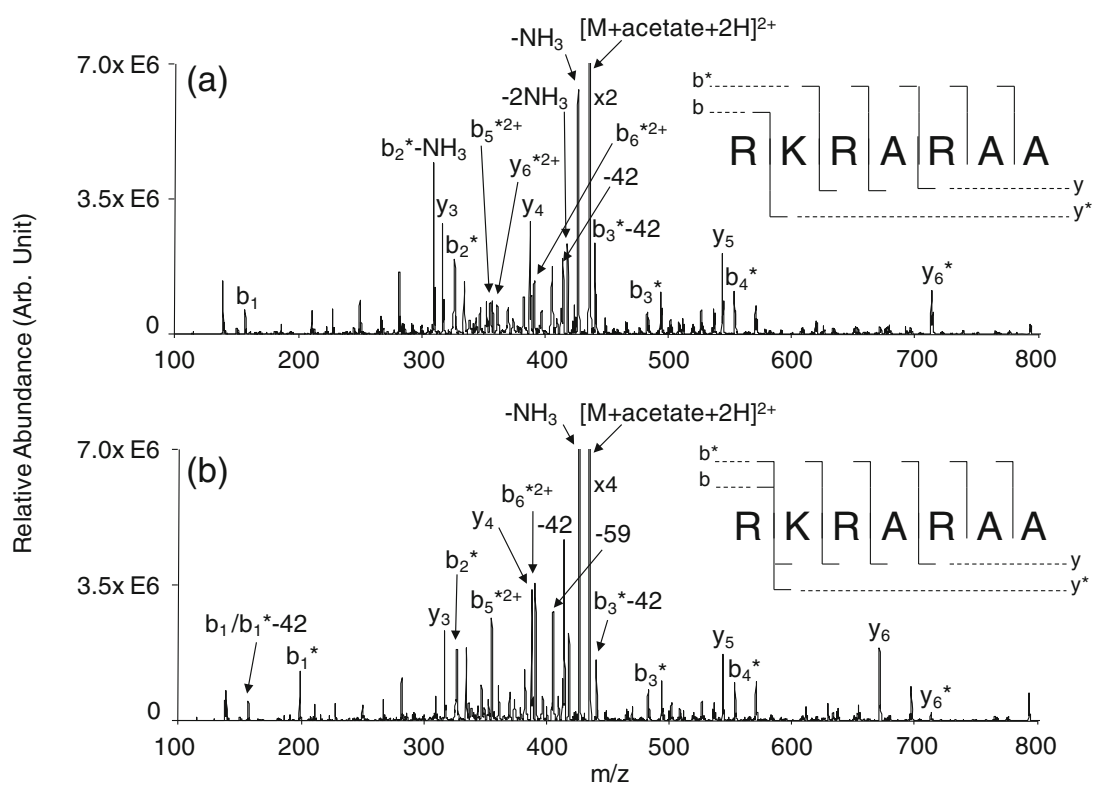

Figure 1. Product ion spectra derived from ion trap CID of $[R K R A R A A+\text { acetate }+2 \mathrm{H}]^{2+}$ generated (a) via ion/ion reaction in the gas phase and (b) in solution at $\mathrm{pH}=5$

The Lys residue near the N-terminus was positioned closer to the C-terminus in RARARKA. Similar to the previous peptide, this peptide was covalently modified in the gas and aqueous phases for comparison. The ion trap CID spectrum of the gas phase modified RARARKA is shown in Figure $2 \mathrm{a}$. All of the b-ions in the spectrum are unmodified except for the $b_{6}$ species. The modified $b_{6}$ ion, however, does not distinguish between the two candidate modification sites. The absence of any other modified b-ions, on the other hand, strongly suggests that little or no modification takes place at the $\mathrm{N}$-terminus. A complete series of modified $\mathrm{y}_{2}-\mathrm{y}_{6}$ ions are observed, which is consistent with modification of the Lys side chain. The ion trap CID spectrum of the $[\text { RARARKA }+ \text { acetate }+2 \mathrm{H}]^{2+}$ complex generated in solution is given in Figure 2b. Since the modification reaction took place at $\mathrm{pH}=5$, modification is expected to be predominantly at the N-terminus. Indeed, the fragmentation behavior of the peptide is consistent with this expectation. An entire series of acetate modified $b_{1}-b_{6}$ ions is observed, while none of the $y$-type ions contains the modification. The dramatic difference in the y-ion series between the peptide-acetate complexes generated in the gas phase versus solution provides strong

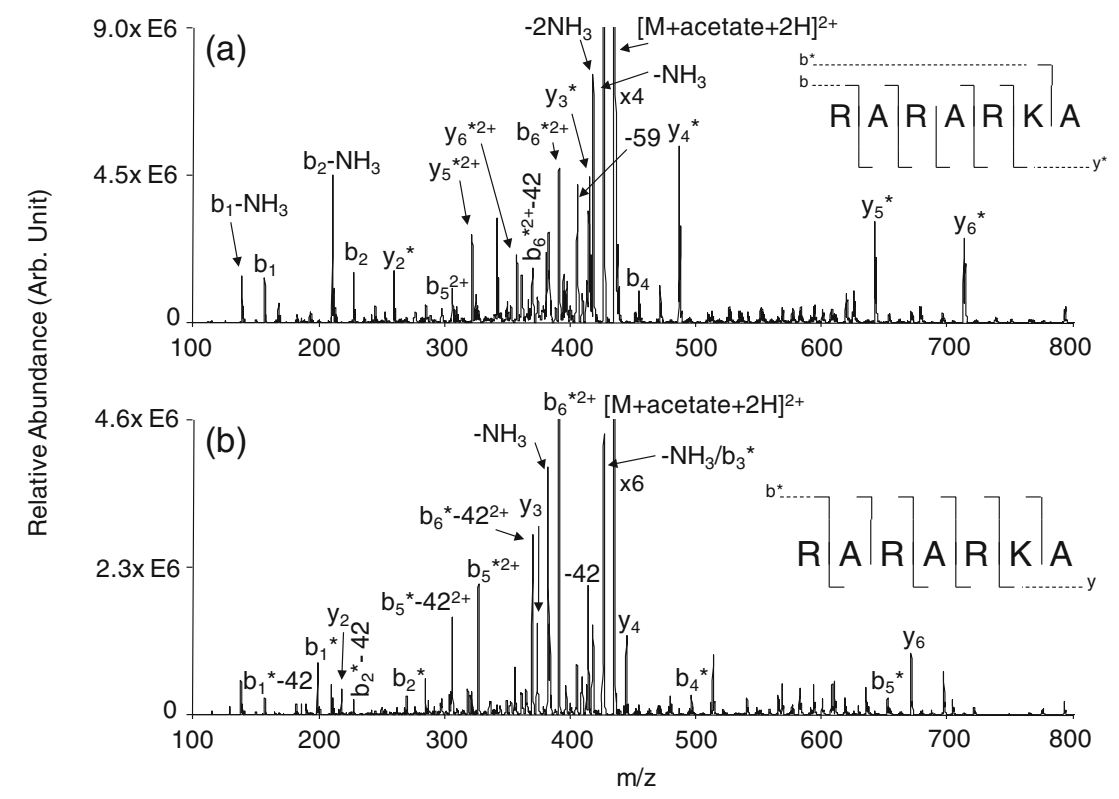

Figure 2. Product ion spectra derived from ion trap CID of $[\text { RARARKA }+ \text { acetate }+2 \mathrm{H}]^{2+}$ generated (a) via ion/ion reaction in the gas phase and (b) in solution at $\mathrm{pH}=5$ 
evidence that the modification in the gas phase preferentially occurred at the Lys side chain primary amine. For comparison, the peptide was modified in solution at $\mathrm{pH}=7$. As expected, at higher $\mathrm{pH}$ both primary amine sites are expected to be unprotonated. The mass spectrum showed exclusive attachment of two acetates (i.e., essentially no evidence for ions with only one acetate attachment was noted). The CID spectrum of the doubly modified ion is provided as Figure S-1 and is fully consistent with modification at both the N-terminus and the lysine residue.

A common characteristic of the CID spectra of the modified peptides discussed so far is the appearance of small neutral molecule losses resulting from cleavages at various positions along the Arg side chain from fragment ions or the precursor ion. One of the common losses from Arg is $42 \mathrm{Da}\left(\mathrm{CH}_{2} \mathrm{~N}_{2}\right)$, which coincidentally corresponds to the acetate modification mass. The peaks in the spectra labeled as being modified with a loss of part of the side chain, such as the $b_{1}{ }^{*}-42$ and $b_{2}{ }^{*}-42$ product ions in Figure $2 b$, were confirmed as such by modifying the peptides with other sulfo-NHS ester reagents, such as sulfo-NHS-AMCA or NHS-biotin. An example is illustrated for data collected for the model peptide ARAKRAR using NHS-biotin (see Figure S-2).

A related model peptide, ARAKARA, was also modified in solution and in the gas phase and the resulting products were compared for sites of modification. The complex formed between singly deprotonated sulfo-NHS-acetate and the triply protonated peptide did not result in sulfo-NHS loss (data not shown), which indicates that no modification occurred. In contrast, when the doubly protonated peptide was reacted with the reagent, modification occurred, as reflected in the loss of sulfo-NHS upon activation of the peptide-reagent complex. The CID spectra of the singly charged gas phase and solution phase modified peptides are shown in Figure S-3. The main difference between this peptide and those discussed above is the replacement of an arginine residue with an alanine residue in the peptide sequence. This change is expected to lead to a significant change in how the peptide stabilizes the excess charge. The lack of reactivity of triply-protonated ARAKARA suggests that all primary amines are involved in solvating the charge to an extent that they are no longer nucleophilic enough to displace sulfo-NHS.

The model peptide RARARAA was used to explore the reactivity of a peptide with only the N-terminus available for reaction. The ion/ion reaction between $[\text { RARARAA }+3 \mathrm{H}]^{3+}$ and [sulfo - acetate $-\mathrm{Na}]^{-}$resulted in complex formation, $[\text { RARARAA }+ \text { sulfo-acetate }+2 \mathrm{H}]^{2+}$. Subsequent collisional activation of this complex resulted in the formation of the intact deprotonated reagent and the singly deprotonated peptide a complete loss of the entire reagent (Figure 3a). The absence of any signal arising from sulfo-NHS loss indicates that no covalent modification of the peptide ion took place in the gas phase. This behavior is similar to that of triply protonated ARAKARA. The excess protons in the peptide ion are likely associated with the three Arg residues, since they are the most basic sites in the sequence [42]. The result of Figure $3 \mathrm{a}$ could be interpreted as indicating that an unprotonated N-terminus is not reactive with the NHS ester or that the charge residing at the N-terminal Arg residue is shared or solvated by the Arg side chain and the N-terminus, thereby diminishing the nucleophilicity of the $\mathrm{N}$-terminus and accounting for its lack of reactivity. A similar observation has been made with doubly protonated KGAGGHGAGGHL in reactions with [FBDSA $-\mathrm{H}]^{-}$[23]. No Schiff base formation was noted with KGAGGHGAGGHL, while reactions with doubly protonated HGAGGKGAGGHL

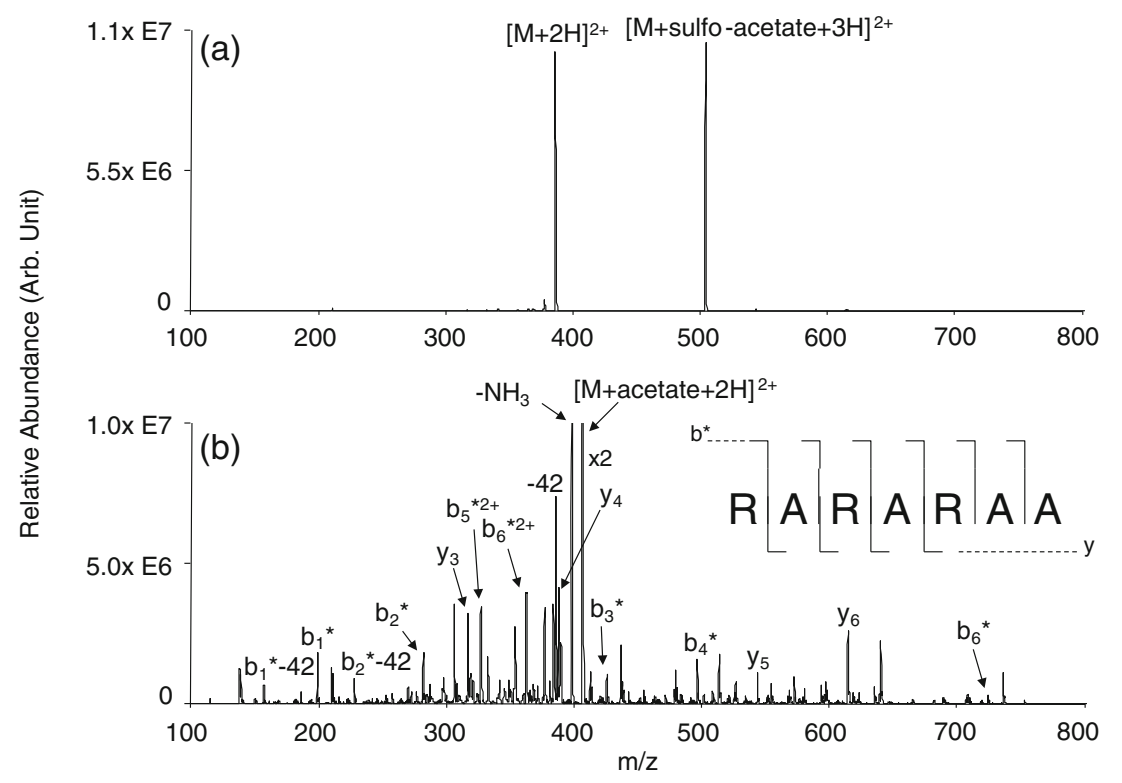

Figure 3. Product ion spectra derived from ion trap CID of (a) $[\text { RARARAA+sulfo-acetate }+3 \mathrm{H}]^{2+}$ generated via ion/ion reaction in the gas phase and (b) [RARARAA+acetate $+2 \mathrm{H}]^{2+}$ generated in solution at $\mathrm{pH}=5$ 
and HGAGGHGAGGKL resulted in Schiff base formation. When singly protonated KGAGGHGAGGHL was reacted with $[\text { FBDSA }-2 \mathrm{H}]^{2-}$, a negatively charged complex was formed that, upon subsequent CID, showed Schiff base formation in the negatively charged peptide. That set of observations clearly indicated that participation of a primary amine in the intramolecular "solvation" of an excess proton can significantly reduce its reactivity as a nucleophile towards a carbonyl carbon in the gas phase. When RARARAA is exposed to sulfosuccinimidyl acetate in solution, the N-terminus is acetylated, as demonstrated in the ion trap CID product ion spectrum of the doubly protonated modified species (Figure 3b). For example, the modified peptide shows a complete series of $b_{1}-b_{6}$ ions containing the modification at the $\mathrm{N}$-terminus, while all of the $\mathrm{y}$-type ions are unmodified. This result indicates that the N-terminus is sufficiently nucleophilic in aqueous solution to react with the sulfo-NHS reagent whereas in the gaseous doubly protonated peptide, it is not.

The data related above show no clear evidence for reaction of the N-terminus with the NHS-ester in the gas phase for any of the model peptides, in clear contrast to the results from reactions in the solution phase. One possibility is that the N-terminus is participating in stabilizing the charge in the gaseous ions, thereby making it unreactive towards the sulfo-NHS-ester. Another possibility is that the unprotonated $\mathrm{N}$-terminus is simply unreactive in the gas phase. There have been several reports demonstrating higher gas phase basicity for Lys relative to $\mathrm{N}$-terminus primary amine [43-48]. If gas-phase proton affinity correlates with nucleophilicity in the gas phase, perhaps the N-terminus is not sufficiently basic to serve as the nucleophile for displacement of the NHS-ester. To address this possibility, a charge inversion reaction was employed so that no excess protons are present on the peptide. In this case, protonated YGGFLK was reacted with the doubly charged anion of bis [sulfosuccinimidyl] suberate $\left(\mathrm{BS}^{3}\right)$, a cross-linking reagent with two sulfo-NHS groups separated by a linker. The doubly charged reagent formed a complex with singly protonated YGGFLK yielding a negatively charged complex, indicated as $\left[\mathrm{M}+\left(\mathrm{BS}^{3}-2 \mathrm{Na}\right)+\mathrm{H}\right]^{-}$. The ion trap CID results for this complex are shown in Figure $4 \mathrm{a}$ along with the structure of the disodium salt of $\mathrm{BS}^{3}$. The main products are singly deprotonated $\mathrm{BS}^{3}$, which indicates that no covalent chemistry took place with some of the peptide ions, and deprotonated sulfo-NHS and a product from the loss of neutral sulfo-NHS, which both indicate the formation of an amide bond between one of the sulfo-NHS groups of $\mathrm{BS}^{3}$ and either the lysine amine group or the $\mathrm{N}$-terminus (or a mixture of the two). Subsequent activation of the ions giving rise to the neutral sulfo-NHS loss peak, labeled as $\left[\mathrm{M}+\mathrm{BS}^{3}-2 \mathrm{Na}-\right.$ (sulfo-NHS) $]^{-}$in Figure 4b, showed losses of either neutral sulfo-NHS or generation of deprotonated sulfo-NHS. Both of these products indicate the formation of a second amide bond with YGGFLK, thereby generating an intramolecularly crosslinked peptide. This result confirms that an unprotonated Nterminus can displace NHS from the NHS-ester to form an amide bond in the gas phase. The appearance of $\mathrm{y}_{1}{ }^{*}$ and $\mathrm{y}_{4}{ }^{*}$ ions, which correspond to $\left[\mathrm{y}_{\mathrm{n}}+\mathrm{BS}^{3}-2 \mathrm{Na}-(\text { sulfo-NHS) }]^{-}\right.$ species, indicate that at least some of the initial covalent bond formation took place at the lysine residue. No $b^{*}$-ions, which would indicate initial attachment to the $\mathrm{N}$-terminus, are apparent in Figure 4b. However, no firm conclusions regarding the relative proportions of the two possible initial attachment sites can be drawn from these observations based on possible differences in the fragmentation behaviors of the two isomeric species that can comprise the $\left[\mathrm{M}+\mathrm{BS}^{3}-2 \mathrm{Na}-(\text { sulfo-NHS) }]^{-}\right.$ population.

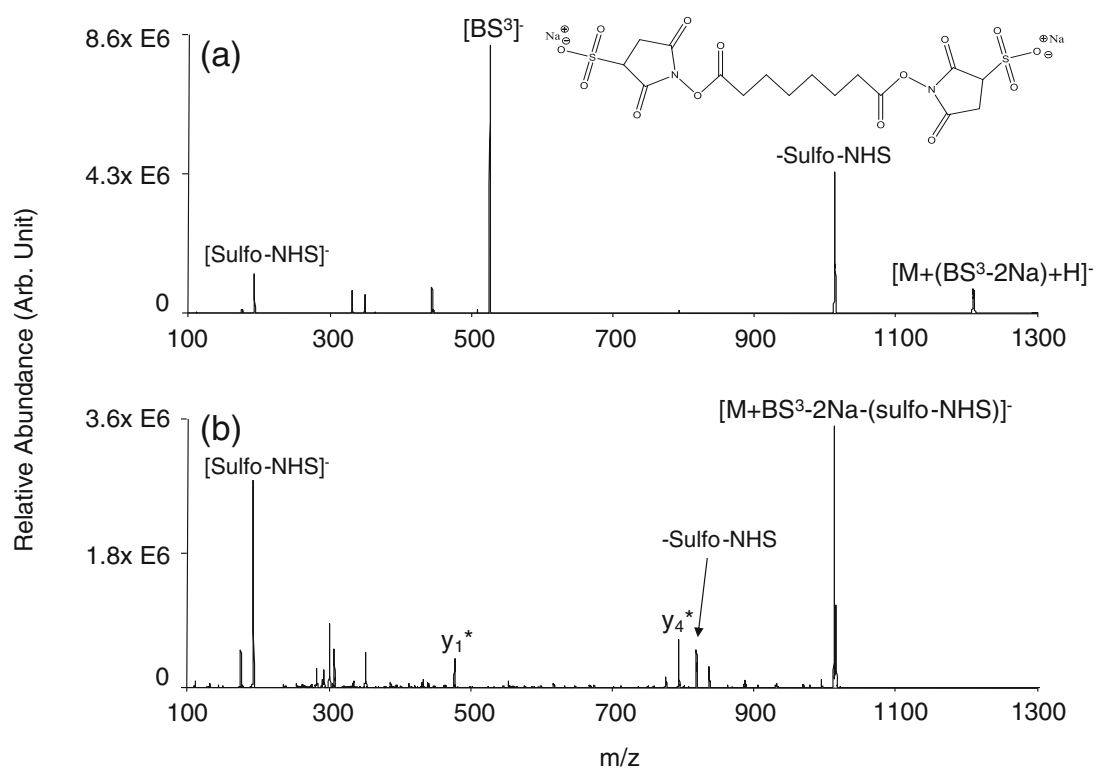

Figure 4. Product ion spectra derived from ion trap CID of the complex (a) $\left[\mathrm{YGGFLK}+\left(\mathrm{BS}^{3}-2 \mathrm{Na}\right)+\mathrm{H}^{-}\right.$generated after charge inversion of $\left[\text { YGGFLK }+\mathrm{H}^{+} \text {with }\left[\mathrm{BS}^{3}-2 \mathrm{Na}\right]^{-} \text {and }(\mathbf{b})\left[\mathrm{YGGFLK}+\mathrm{BS}^{3}-2 \mathrm{Na}-\text { (sulfo }-\mathrm{NHS}\right)\right]^{-}$generated from the experiment in (a) 


\section{Conclusions}

Primary amines can act as nucleophiles in the displacement of $N$-hydroxysuccinimide from NHS-esters in both aqueous solution and the gas phase. The interaction of the nitrogen lone pair with a positive charge can significantly reduce the nucleophilicity of the amine and, as a result, its reactivity with NHS esters both in aqueous solution and in the gas phase. However, ionization states and charge solvation can differ dramatically between the two phases, which can lead to differences in the reactivities of primary amines within a given peptide for solution phase and gas phase species. In all cases studied here, the sites of modification by sulfo-NHSacetate differed in solution and in the gas phase. In the case of aqueous solution, the adjustment of $\mathrm{pH}$ can be used either to modify the N-terminus selectively or to modify both the $\mathrm{N}$-terminus as well as exposed lysine residues. The ability to alter the sites of protonation in solution via $\mathrm{pH}$ results from the difference in the pKa values of the N-terminus and the $\varepsilon$ amino group of lysine. The sites of protonation in gaseous peptide ions, on the other hand, can differ from those in aqueous solution and, in the absence of the dielectric of water, multiple sites can act to 'solvate' the excess charge on the ion. For example, the reactivities of some of the gaseous peptide cations in this work suggest that the N-terminus engages to some degree in solvating excess charge (see, for example, the results for triply-protonated RARARAA). It is demonstrated in this work that both the unprotonated $\mathrm{N}$ terminus and the $\varepsilon$-amino group of lysine are reactive towards sulfo-NHS-esters. It is not clear from these studies, however, if there is a significant difference in the inherent reactivities of these sites due to the overriding importance of charge solvation and the variability with which this can occur in gas phase peptides as functions of sequence and composition. This variability makes prediction of the site of modification less certain when conducted in the gas phase than in aqueous solution at known $\mathrm{pH}$.

\section{Acknowledgment}

The authors acknowledge support for this research by the Office of Basic Energy Sciences, Office of Science, U.S. Department of Energy, under Award DE-FG02-00ER15105 and the National Institutes of Health under Grant GM 45372.

\section{References}

1. Ogorzalek Loo, R.R., Udseth, H.R., Smith, R.D.: A new approach for the study of gas-phase ion-ion reactions using electrospray ionization. $J$. Am. Chem. Soc. 3, 695-705 (1992)

2. Pitteri, S.J., McLuckey, S.A.: Recent developments in the ion/ion chemistry of high-mass multiply charged ions. Mass Spectrom. Rev. 24 931-958 (2005)

3. McLuckey, S.A., Stephenson Jr., J.L.: Ion/ion chemistry of high-mass multiply charged ions. Mass Spectrom. Rev. 17, 369-407 (1998)

4. Scalf, M., Westphall, M.S., Krause, J., Kaufman, S.L., Smith, L.M.: Controlling charge states of large ions. Science 283, 194-197 (1999)

5. McLuckey, S.A.: The emerging role of ion/ion reactions in biological mass spectrometry: Considerations for reagent ion selection. Eur. J. Mass. Spectrom. 16, 429-439 (2010)
6. Stephenson Jr., J.L., McLuckey, S.A.: Ion/ion reactions in the gas-phase: Proton transfer reactions involving multiply-charged proteins. J. Am. Chem. Soc. 118, 7390-7397 (1996)

7. Scalf, M., Westphall, M.S., Smith, L.M.: Charge reduction electrospray mass spectrometry. Anal. Chem. 72, 52-60 (2000)

8. Ogorzalek Loo, R.R., Udseth, H.R., Smith, R.D.: Evidence of charge inversion in the reaction of singly charged anions with multiply charged macroions. J. Phys. Chem. 95, 6412-6415 (1991)

9. Emory, J.F., McLuckey, S.A.: Charge inversion of polypeptide anions using protein and dendrimer cations as charge inversion reagents. Int. J. Mass Spectom. 276, 102-109 (2008)

10. He, M., McLuckey, S.A.: Two ion/ion charge inversion steps to form a doubly-protonated peptide from a singly-protonated peptide in the gas phase. J. Am. Chem. Soc. 125, 7756-7757 (2003)

11. He, M., McLuckey, S.A.: Increasing the negative charge of a macroanion in the gas phase via sequential charge inversion reactions. Anal. Chem. 76, 4189-4192 (2004)

12. Newton, K.A., McLuckey, S.A.: Gas-Phase Peptide/Protein Cationizing Agent Switching via Ion/Ion Reactions. J. Am. Chem. Soc. 125, $12404-$ 12405 (2003)

13. Gunawardena, H.P., O’Hair, R.A., McLuckey, S.A.: Selective Disulfide Bond Cleavage in Gold(I) Cationized Polypeptide Ions Formed Via Gas-Phase Ion/Ion Cation Switching. J. Proteome Res. 5, 2087-2092 (2006)

14. Payne, A.H., Glish, G.L.: Gas-phase ion/ion interactions between peptides or proteins and iron ions in a quadrupole ion trap. Int. J. Mass Spectrom. 204, 47-54 (2001)

15. Herron, W.J., Goeringer, D.E., McLuckey, S.A.: Gas-phase electron transfer reactions from multiply-charged anions to rare gas cations. $J$. Am. Chem. Soc. 117, 11555-11562 (1995)

16. Syka, J.E.P., Coon, J.J., Schroeder, M.J., Shabanowitz, J., Hunt, D.F.: Peptide and protein sequence analysis by electron transfer dissociation mass spectrometry. Proc. Natl. Acad. Sci. U.S.A. 101, 9528-9533 (2004)

17. Coon, J.J., Shabanowitz, J., Hunt, D.F., Syka, J.E.P.: Electron transfer dissociation of peptide anions. J. Am. Soc. Mass Spectrom 16, 880-882 (2005)

18. Reid, G.E., Shang, H., Hogan, J.M., Lee, G.U., McLuckey, S.A.: Gas-phase concentration, purification, and identification of whole proteins from complex mixtures. J. Am. Chem. Soc. 124, 73537362 (2002)

19. Liu, J., Huang, T.-Y., McLuckey, S.A.: Top-down protein identification/ characterization of a priori unknown proteins via ion trap collision-induced dissociation and ion/ion reactions in a quadrupole/time-of-flight tandem mass spectrometer. Anal. Chem. 81, 1433-1441 (2009)

20. Huang, T.-Y., Liu, J., Liang, X., Hodges, B.D.M., McLuckey, S.A.: Topdown analysis of siRNA via ion trap collision-induced dissociation. Anal. Chem. 80, 8501-8508 (2008)

21. Huang, T.-Y., Liu, J., McLuckey, S.A.: Top-down tandem mass spectrometry of a tRNA via ion trap collision-induced dissociation. $J$. Am. Soc. Mass Spectrom. 21, 890-898 (2010)

22. Han, H., McLuckey, S.A.: Selective covalent bond formation in polypeptide ions via gas-phase ion/ion reaction chemistry. J. Am. Chem. Soc. 131, 12884-12885 (2009)

23. Hassell, K.M., Stutzman, J.R., McLuckey, S.A.: Gas phase bioconjugation of peptides via ion/ion charge inversion: Schiff base formation on the conversion of cations to anions. Anal. Chem. 82, 1594-1597 (2010)

24. Stutzman, J.R., Hassell, K.M., McLuckey, S.A.: Dissociation behavior of tryptic and intramolecular disulfide-linked peptide ions modified in the gas phase via ion/ion reactions. Int. J. Mas. Spectrom (2011). doi:10.1016/j.ijms.2011.07.002

25. Mentinova, M., McLuckey, S.A.: Covalent modification of gaseous peptide ions with n-hydroxysuccinimide ester reagent ions. J. Am. Chem. Soc. 132, 18248-18257 (2010)

26. Mentinova, M., McLuckey, S.A.: Intra- and inter-molecular crosslinking of peptide ions in the gas phase: Reagents and conditions. J. Am. Soc. Mass Spectrom. 22, 912-921 (2011)

27. Yang, W.C., Mirzaei, H., Liu, X.P., Regnier, F.E.: Enhancement of amino acid detection and quantification by electrospray ionization mass spectrometry. Anal. Chem. 78, 4702-4708 (2006)

28. Gygy, S.P., Rist, B., Gerber, S.A., Turecek, F., Gelb, M.H., Aebersold, R.: Quantitative analysis of complex protein mixtures using isotope-coded affinity tags. Nat. Biotechnol 17, 994-999 (1999) 
29. Ross, P.L., Huang, Y.L.N., Marchese, J.N., Williamson, B., Parker, K., Hattan, S., Khainovski, N., Pillai, S., Dey, S., Daniels, S., Purkayastha, S., Juhasz, P., Martin, S., Bartlet-Jones, M., He, F., Jacobson, A., Pappin, D.J.: Quantitative analysis of complex protein mixtures using isotope-coded affinity tags. Mol. Cell. Proteom. 3, 1154-1169 (2004)

30. Beardsley, R.L., Sharon, L.A., Reilly, J.P.: Peptide de novo sequencing facilitated by a dual-labeling strategy. Anal. Chem. 77, 6300-6309 (2005)

31. Madsen, J.A., Brodbelt, J.S.: Simplifying fragmentation patterns of multiply charged peptides by n-terminal derivatization and electron transfer collision activated dissociation. Anal. Chem. 81, 3645-3653 (2009)

32. Knock, S.L., Miller, B.T., Blankenship, J.E., Nagle, G.T., Smith, J.S., Kurosky, A.: $N$-acylation of Aplysia egg-laying hormone with biotin. Characterization of bioactive and inactive derivatives. J. Biol. Chem 266, 24413-24419 (1991)

33. Novak, P., Kruppa, G.H., Young, M.M., Schoeniger, J.: Top-down method for the determination of residue-specific solvent accessibility in proteins. J. Mass Spectrom. 39, 322-328 (2004)

34. Natarajan, S.K., Assadi, M., Sadegh-Nasseri, S.: Stable peptide binding to $\mathrm{MHC}$ class II molecule is rapid and is determined by a receptive conformation shaped by prior association with low affinity peptides. $J$. Immunol. 162, 4030-4036 (1999)

35. Baker, D.P., Lin, E.Y., Lin, K., Pellegrini, M., Petter, R.C., Chen, L.L., Arduini, R.M., Brickelmaier, M., Wen, D., Hess, D.M., Chen, L., Grant, D., Whitty, A., Gill, A., Lindner, D.J., Pepinsky, R.B.: N-Terminally PEGylated human interferon- $\beta-1 \mathrm{a}$ with improved pharmacokinetic properties and in vivo efficacy in a melanoma angiogenesis models. Bioconj. Chem. 17, 179-188 (2005)

36. Wang, P., Hadjar, O., Gassman, P., Laskin, J.: Reactive landing of peptide ions on self-assembled monolayer surfaces: An alternative approach for covalent immobilization of peptides on surfaces. J. Phys. Chem. Chem. Phys. 10, 1512-1522 (2008)
37. Hermanson, G.T.: Bioconjugate Techniques, 2nd edn. Academic Press, Amsterdam (1998)

38. Hager, J.W.A.: A new linear ion trap mass spectrometer. Rapid Commun. Mass Spectrom. 16, 512-526 (2002)

39. Liang, X., Xia, Y., McLuckey, S.A.: Alternately pulsed nanoelectrospray ionization/atmospheric pressure chemical ionization for ion/ion reactions in an electrodynamic ion trap. Anal. Chem. 78, 3208-3212 (2006)

40. Xia, Y., Wu, J., Londry, F.A., Hager, J.W., McLuckey, S.A.: Pulsed dual electrospray ionization for ion/ion reactions. J. Am. Soc. Mass Spectrom. 16, 71-81 (2005)

41. Londry, F.A., Hager, J.W.: Mass selective axial ion ejection from a linear quadrupole ion trap. J Am Soc Mass Spectrom. 14, 1130-1147 (2003)

42. Hunter, E.P., Lias, S.G.: Evaluated gas phase basicities and proton affinities of molecules: An update. J. Phys. Chem. Ref. Data 27, 413656 (1998)

43. Gorman, G.S., Speir, J.P., Turner, C.A., Amster, I.J.: Proton affinities of the 20 common $\alpha$-amino acids. J. Am. Chem. Soc. 114, 3986-3988 (1992)

44. Wu, Z., Fenselau, C.: Proton affinity of arginine measured by the kinetic approach. Rapid Commun. Mass Spectrom. 8, 777-780 (1994)

45. Bojesen, G., Breindahl, T.: On the proton affinity of some $\alpha$-amino acids and the theory of the kinetic method. J. Chem. Soc. Perkin Trans. 2, 1029-1037 (1994)

46. Merrill, G.N., Fletcher, G.D.: The prediction of gas-phase and aqueous basicities for alkyl amines. J. Mol. Struc. Theochem. 849, 84-97 (2008)

47. Gorman, G.S., Amster, J.I.: Gas-phase basicity measurements of dipeptides that contain valine. J. Am. Chem. Soc. 115, 5729-5735 (1993)

48. Carr, S.R., Cassady, C.J.: Gas-phase basicities of histidine and lysine and their selected di- and tripeptides. J. Am. Soc. Mass Spectrom. 7, 1203-1210 (1996) 